Design for Human Flourishing: a novel design approach for a more 'humane' architecture

Peer-reviewed author version

STEVENS, Ruth; PETERMANS, Ann \& VANRIE, Jan (2019) Design for Human Flourishing: a novel design approach for a more 'humane' architecture. In: The design journal, 22 (4), p. 391-412.

DOI: $10.1080 / 14606925.2019 .1612574$

Handle: http://hdl.handle.net/1942/28010 


\title{
Design for Human Flourishing: a novel design approach for a more 'humane' architecture
}

\begin{abstract}
Architects today still highly rely on intuition attempting to handle more emotional, well-being-related design requests of clients. It seems that newly formed design demands present challenges that cannot be fully answered through the current existing design paradigms. Additionally, a 'humanization' trend in architectural design can be noticed of influences that steer architecture on a more 'humane' course, thereby advocating the viability of 'well-being' as a structured design approach in architecture. This paper aims to answer to this current momentum in architecture, by explicating a novel design approach called 'Design for Human Flourishing' (DfHF), based on a literature study of well-being theory through an architectural lens. Concretely, five well-being related attributes will be identified that define DfHF's characteristics. Furthermore, what DfHF means in architectural practice will be illustrated via a design example.
\end{abstract}

Keywords: architecture, well-being, human flourishing, design approach

Subject classification codes: architecture, design and wellbeing, human-centred design

\section{A humanization trend depicts a need for a more 'humane' design course in architecture}

\section{Internal evolutions}

Architecture is a comprehensive design discipline subject to undulations in society, regulation, technology and much more, causing the profession to change in recent times. Currently, some internal changes mark a humanization trend. We have noticed that the scale of architectural firms is enlarging. The augmenting numbers of co-workers include architect-partners, project architects, researchers, calculators, technical designers, interior architects, stability experts, and others, who all have specific tasks in one project. Aspects such as sustainability and accessibility, once small particles in an architectural design process, have grown to become disciplines on their own, and 
thereby outdating the $19^{\text {th }}$ and $20^{\text {th }}$ century image of architecture being an 'all round discipline'. Thus, while the scale of the architectural firm is enlarging, the expertise of the architect is more focused and channelled regarding talents and interests.

Moreover, larger firms are known to initiate an in-house research group, to deepen the knowledge and nourish design practice. A well-known example is AMO, the in 1998 founded think tank within the globally active architectural firm Office for Metropolitan Architecture lead by architect Rem Koolhaas (OMA, 2017).

Additionally, firms experiment with a more engaging role, by for instance carrying out projects themselves, based on their vision on a societal 'problem' or negatively appraised situation. The Belgian based design bureau OSAR’s head launched a non-profit organization that developed the care typology of Astor, a demand-driven architectural concept to counter the current the supply-based vision in residential care (OSAR, 2017). Globally, architects engage in participatory design projects with local communities, or undertake activities to improve living conditions after calamitous events, such as the organization Architects Without Borders (ASF-Belgium, 2017). Or architects engage in 'giving buildings back to the public', illustrated by the local Belgian initiative in which architects started a public protest to safeguard the city beguinage ${ }^{1}$ of Hasselt from being sold to a private project developer. They hammered on the beguinage's unique role as a green and peaceful area in the city centre that should remain open to locals and visitors (De Ridder, 2016). Another example of the social role of an architect can be found in the award-winning Chilean architect Alejandro Aravena (see Aravena, 2014), founder of the 'Do Tank Elemental’ that builds

\footnotetext{
${ }^{1}$ An architectural complex of small houses in a row or often built around a square, created to house beguines, lay religious women.
} 
social housing in close cooperation and dialogue with the living community (Elemental, 2017).

\section{External influences}

\section{Confrontation with Zeitgeist}

In the past, architects have been criticized for having only a limited understanding of the relationship between clients and the built environment (e.g. Brolin, 1976; Lang, 1987; Bogers et al., 2008) and for using a rather limited model of human behaviour (Stringer, 1980). What do clients' needs primarily entail? Objective, more tangible needs, such as the need for having a roof above one's head? Or more intangible, such as the need to feel in control in an environment? Or both? In the industrialized Western world, the balance between answering our (sometimes saturated) tangible and our (rather undervalued) intangible needs had tilted towards the more intangible needs. Applied to the built environment, people seem to be rediscovering the relevance of genuine social contact and cultural life, for instance in public spaces, to express who they really are, maybe partly as a reaction against their digital lifestyle (Hadelich, 2012), and find wellbeing in the meaning attributed to their home environment (Silva, 2011). Sketched in a caricatured way; the design, look and feel of the spatial setting we live in is also a logical place to express who we are.

\section{Evolving design briefs}

The humanization trend is also exemplified by the design briefs clients deliver today, expressing emotions and experiences rather than mere physical demands, emphasizing what one can experience in an environment, and how these experiences comply with one’s behaviour. A well-known example of a building realized with more attention to the humane experiential aspect of the building is 'Maggie’s Centre’ that grew out of a 
specific experiential design brief. In this brief, the design demands regarded much more the feel and atmosphere in the environment, for instance the requests for the possibility to cry privately or the opportunity to drink coffee in a family atmosphere (Maggie's architectural brief, 2011; Van der Linden et al., 2016), which sets a different tone than for instance requesting five office spaces or a large kitchen. However, these realizations seem to arise out of intuitions, personal experience or gut feeling of the designer rather than out of a conscious strategic methodology (Van der Linden et al., 2016). In 2004, Bogers and colleagues already opted for the inclusion of qualitative information in the design brief, such as personal statements of users. However sociological information on what user groups wish to 'experience' in a building, is more difficult to take into account by architects, who were not trained in that manner (e.g. Tétreault \& Passini, 2003). Thus, the challenge of the changing design briefs lies in finding ways to incorporate and accommodate the information.

\section{Experiential architecture}

As Lang argued in 1987 and Maier and colleagues (2009) repeated two decades later, architecture is still developing a necessary as well as rigorous theoretical basis on how people interact with environments. Unfortunately, compatibility between user and environment was often lost in contemporary architecture, as indicated by designers who question the habitability of environments (Attiwill, 2013). Jan Gehl, in his effort to sensitize architects to create desirable and liveable 'cities for people' advocates for social and psychological knowledge in the metier of an architect (Oppliger, 2015). Very recently, Rem Koolhaas stressed the social motivation architecture should carry out, but then 'the architect has to be sociologist, anthropologist and try to understand how the world works’ (Koolhaas, 2016, n.p.). So, architect critics with a phenomenologist approach seem to place focus on a more complete, holistic architectural experience by 
stressing the importance of adopting a sense of empathy towards clients while designing (Pallasmaa, 2005; Holl et al., 2007).

This humanization trend indicates that architects are on their way to design more empathically. But to further face this humanization trend, architects will need to even better interpret in a 'humane' sense what a client is requesting, then try to translate that information into designed functions and activities afforded by the environment, that when undertaken, aim to trigger the actual 'experiences' that clients requested. In that respect, the DfHF approach considers architecture as a dynamic context instead of as a passive platform.

\section{From well-being interest towards a novel design approach: Design for Human Flourishing (DfHF)}

The changes described above have seemed to create a momentum for a more 'humane' architecture. Zooming in on the architectural design field, it seems that it is still scattered with intuitive efforts of architects who are trying to answer the momentum for this more humane architecture. In practice many architects do already take well-being into account in their work, but this is (too) often (too) implicit or with an ill-defined concept of well-being in mind, usually highlighting specific aspects such as social integration (in e.g. the social housing industry). As the design world in general has come to know 'human-centred design' that contains a number of well-funded and structured approaches, we feel the discipline of architecture would also benefit by a clearly defined content of well-being driven, 'humane' architecture. This would provide structure to architects’ efforts towards a more systematic approach for designing 
buildings and interiors conducive to people’s well-being.

Concretely, the avenue we take in exploring a more 'humane' architecture is integrating the topic of 'human flourishing' (HF) as a starting point for creating architecture. HF is more specified than the general overarching concept of 'well-being', that has been interpreted many times throughout many design branches but still lacks a clear definition and content. Moreover, the concept of well-being has a number of connotations, making it more difficult to apply as a design concept, contrary to HF, which is a relatively new concept in design research, a 'science in its infancy' (Schotanus-Dijkstra and colleagues, 2015, p. 5). HF, as perhaps the most ambitious interpretation of well-being, comes with a clear content and definition, namely ‘a human process leading to self-actualization or becoming the 'best' person one can be, by fulfilling one’s psychological needs and applying and developing one’s personal talents...' (Author, 2018), which is operationalized in architecture: ... 'here by consciously and actively interacting with the designed environment that surrounds one.' (Author, 2018).

\section{Distilling five attributes to mark the flourishing potential in human-centred architecture and distinguish the position of DfHF}

To explicate a concept as DfHF and position it into design practice, it is necessary to define and concretize the approach of DfHF and find aspects where DfHF -and its architectural realizations- clearly discerns oneself from other paradigms or approaches that show affinity with DfHf regarding an influence on people's well-being -we call these 'friendly paradigms'. To guide this process, out of well-being literature studied 
through an architectural lens, five attributes $^{2}$ were distilled that mark important differences on a range between a flourishing-supportive characteristic in an architectural design, or another well-being related influence of a design (e.g. merely objective wellbeing (OWB) or subjective well-being (SWB)). The attributes handle aspects that manifest themselves (i) in the design attitude of the designer, (ii) in the effect the designer aims to accomplish, or (iii) the characteristics of the eventual design outcome. Afterwards, we will use these five attributes to further define and concretize the paradigm of DfHf from a practitioner's viewpoint.

\section{Fleeting versus long-term durable effect}

Well-being has been interpreted by some authors as a rather one-dimensional concept, for instance focused on positive emotions and positive affect (e.g. see Diener et al, 1998; Kahneman, 1999, Diener, 1999; Ryan \& Deci, 2000) and by other authors as a multidimensional concept, that also includes aspects such as meaning and the 'good life’ (e.g. Ryff, 1989; Ryff \& Keyes, 1995, Seligman, 2011). These different interpretations can be brought back to the original hedonic and eudaimonic views on well-being (see Author, 2018). These two interpretations of well-being also imply different approaches when it comes to trying to augment people's well-being through design. From a hedonic perspective, one would suggest to a designer to focus on shortterm, direct effects, since a hedonic approach to well-being is built on fleeting emotions and momentary pleasures (Tiberius, 2007), i.e. positive and negative affect (e.g. Diener, 1999). This approach largely ignores aspects such as self-actualization (cf. Maslow, 1954) or virtuous behaviour (Desmet \& Pohlmeyer, 2013). On the other hand, the

\footnotetext{
2 These five attributes do not pretend to be an exhaustive list to compare the HF- or WB-character of a design by, but do provide a holistic view for comparison.
} 
eudaimonic perspective requires a larger time frame, reflecting on what makes up a good and meaningful life, and what makes a person strive for excellence and higher goals (Keyes, 2002; Seligman, 2011). According to this perspective, one would suggest a designer to aim for a long-term impact.

Extrapolated to the field of architectural design, as such, the durability of the intended effects is a first attribute that can mark a range between either a flourishing characteristic or a more toned down well-being effect (e.g. OWB, SWB). Humancentred design paradigms can differ between fleeting and durable effects on users.

\section{Physical versus psycho-emotional effect}

In well-being theory, one can find interpretations ranging from more medical, biological or physical descriptions, to psychological, emotional and social aspects, including philosophical debates on meaning and how to lead a virtuous life (e.g. Headey et al., 1985). However, there is consensus on the importance of integrating both physical and more psychological aspects in the debate, as evidenced by the definitions of 'health' by the World Health Organization as standing for not only the absence of ill-health, but 'a state of complete physical, mental and social well-being' (WHO, 2001). Nevertheless, when looking at architectural efforts with the purpose of increasing well-being up to HF, a distinction can be found ranging from the emphasis that is placed on either the physical or the psycho-emotional effect on users. This can be seen as a second important differentiating attribute.

\section{Compensating negative versus stimulating positive as starting vision}

In well-being research, it used to be tacitly assumed that well-being would arise when a particular pathology or negatively appraised situation (i.e. ill-being) was absent or countered. However, to understand a concept such as HF, in which people try to be the 
best person they can be, this concept needs to be studied it in its own right (Keyes, 2007; Huppert \& So, 2013). More specifically, one must start from the positive premise of researching how something positive can mature and become even more positive (e.g. aspects such as personal skill level), independently of possible negative border issues, as illustrated by the field of positive psychology. A clear link with this duality present in existing well-being theories can be found in the concept of Salutogenesis, proposed by Antonovsky $(1979,1996)$. Antonovsky saw health as a movement in a continuum between ill-health (dis-ease) and total health (ease) (Lindström \& Eriksson, 2005, 2008; Eriksson \& Lindström, 2012) and he proposed a focus on the positive, i.e., the direction towards overall health, instead of the (in his time) classic focus on fighting ill-health, and preventing risks.

In the field of design, approaches that start from and turn around a more negatively appraised situation are already present, as Rosenman and Gero (19986, p. 163) describe design as 'a purposeful activity to arrive at a state which not previously exists in order to (presumably) improve some (perceived) unsatisfactory existing state of affairs'. However, recently, Dilani (2005) extrapolated Antonovsky’s vision to architectural design, by stating that Salutogenesis should be the starting point for theoretical approaches for design that not only aim to promote health but also to support users psycho-emotionally.

Thus, a third differentiating attribute is the premise that designers start from, marked by a continuum between avoiding or compensating the negative, or creating or upgrading the positive. This premise not only marks the starting vision of the designer at the beginning of the project, but also entails the entire mindset in the design process.

\section{Passive versus active user (or tangible versus intangible outcome)}

Antonovsky stated that our inner resources are a key factor in a health promotion 
approach; recognizing and using these, would lead to an orientation of life conducive to overall health, well-being and quality of life (Antonovsky, 1979; Lindström et al, 2010). In well-being research, the research of Lyubomirsky $(2005,2007)$ has learned that one's happiness is for $40 \%$ dependent on the intentional activities that one undertakes. In HF, Antonovksy’s (1979) and Lyubomirsky’s (2005, 2007) insights come together, and the emphasis is placed on the positive possibilities of our inner resources and on invoking the human capacity to recognize opportunities for actively exploiting inner resources and talents, in order to achieve a positive and self-actualizing experience. Saleebey (2006) labels this a perspective based on strengths, focusing on supporting people’s capabilities and increasing the inner resources level, an eudaimonic vision. Throughout the literature touched upon here, a more active role is attributed to the user, who needs to actively appeal on his resources and talents, and actively undertake activities.

Bridging well-being and design research, Desmet and Pohlmeyer (2013, p. 6) stated 'It is not the products or their material value, but what we do with products that can make us happy’. This marks an evolution in design research and practice from designing of (e.g. objects or stimuli in environments) to designing for (e.g. services, experiences in environments or emotions). Extrapolating this to an architectural context, there is a similarity between what we have earlier called designing for objective wellbeing (OWB) or designing for subjective well-being (SWB. A focus on OWB lead to designing stimuli that are directly perceivable through sensory interaction with the environment. In case of the latter, designing for SWB, and even more so in DfHF, the focus is placed on designing experiences. This way of working first and foremost approaches the user as an active and mentally present person that can recognize suitable (designed) activities, but it also entails an active understanding of the user, and a genuine interest of the involved designer in what can help that user flourish. 
In short, the role of the user is a fourth differing attribute, which can range between respectively passively consuming, and actively participating in the environment. However, to evaluate and discuss this attribute in an architectural context, this can be represented by the focus on designing objective stimuli (related to OWB) or designing for intangible experiences (related to SWB, and HF). Therefore, extrapolated to the context of architectural design, this attribute will be named a continuum between tangible or intangible design outcome.

\section{Narrow versus broad scope}

In the light of eudaimonic views that depart from a capabilities approach, in which a list of people’s objective values is key (see e.g. Ryff \& Singer, 1998), what about the heterogeneity of the target group of 'people’? Brey (2015) even questions whether it is even possible to draw up a list of values that would be valid for 'most' people. For instance, the flourishing model of PERMA ${ }^{3}$ is generally applicable, but is in need for deepening and specification when using in it a specific context. We thus raise the question to what extent well-being related attempts are target group-dependent.

Extrapolating to an architectural context, the target group of a designed environment is often difficult to determine. For instance in a theatre or library, a multitude of users ranging from young to old or from physically fit to physically challenged can be present. Even within buildings with an at first sight clearly defined target group, such as school environments, the character and psychological needs of the users of the building can differ. Regarding target groups, some issues are general for architects to incorporate, such as the biological need to be able to breathe. However, 
other aspects seem to be more group bound, such as the need to learn in a school environment. Other issues can relate to very personal needs of users regarding the spatial context they are in, for instance the preference of having desks placed in a circle, two by two, or separately in a classroom. In architectural design, there is a fundamental difference between the targeted 'user' of a building, and the actual (characteristics of the) person(s) that will occupy and use the building, and that can even change overtime, such as the needs and preferences of a 6-year old versus these of a 12-year old in school buildings. In the light of HF, and to conduct a more 'humane' design process, architects will need to bridge these two by creating a virtual target group, and defining their present and maybe even future characteristics and needs to anticipate on these via the design. This can be illustrated by what architects already do on a smaller scale; when designing one's private house, the architect departs from current needs and wishes but also envisages that person having a family, growing old and challenging physical burdens, at least to some extent. From a humane perspective, understanding and incorporating the needs of the clients, also entails extrapolating these personal needs in a specific generally applicable context, by looking at the 'user client' with a specific lens in mind.

Thus, the way the 'user' is approached, seems a fifth important differing attribute characterizing the design process of human-centred design paradigms. We refer to this as the approached scope, which can range between rather narrow, rather homogeneous or rather broad, heterogeneous.

\section{Using five attributes to define and position DfHF in human-centred architecture}

These five attributes, that are summarized in the right part of Table 1, are fit to discuss well-being related aspects that either surface in (i) the architectural design process, (ii) the intended effect the designers aims to accomplish on the users, or (iii) the 
architectural design outcome. That way, the attributes can sketch a holistic image.

\section{[Table 1 near here]}

Table 1: List of comparing attributes and their continuum to profile human-centred design paradigms in architectural practice

The first attribute 'compensating negative versus stimulating positive', describes to some extent the starting vision of the architect, and the mindset that will be followed throughout the design process. The second attribute 'tangible outcome versus intangible outcome', was primarily introduced as 'passive versus active user'. However, in an architectural context that can be related to the nature of the design outcome, whether the design is directly perceivable and picked up through the senses of the user, without mental effort and interpretation, or whether the user in the environment needs to actively interpret the environment and recognize opportunities for activities to undertake that match the needs and wishes of the user. The third attribute 'physical versus psycho-emotional effect', describes what kind of effect the architect aims to generate through his/her design. The fourth attribute 'fleeting versus long-term, durable effect', provides more information on the duration of the generated effect, and thereby also on its generosity: this attribute handles the question of whether the generated effect will remain active and influence the user in a positive way after he/she has left the designed environment. In our view, an effect can be labelled generous, when it has longevity. The fifth attribute regarding the scope concerns how broadly the characteristics of a target group are approached, or in other words, the homogeneity or heterogeneity of the target group interpreted in the design process. It explains to what extent a targeted audience have one or more aspects in common, such as gender, age, pathology, etcetera. 
The five attributes visualized in Table 1, each represent their continuum between the two -what we call- 'extremes', in which a design approach takes a stand by situating themselves explicitly on one side, or carry bits of both of the 'extremes' of the continuum per attribute, and be situated more towards the centre.

\section{Explicating and concretizing DfHF via the five attributes}

To introduce DfHF in human-centred architectural design, we will explain DfHF from a designer's perspective via the five aforementioned attributes. To make it more graspable, we will draw DfHF's position out into a figure that explicates the stand towards the five attributes. These stands are marked by five sliders ${ }^{4}$ that take a position in-between the two extremes per attribute. All sliders in the figure have the same length, and express the differences in design emphasis with regards to that respective attribute. The five tail ends of the sliders are connected resulting in a coloured polyhedron, whereby a humane "identity card” is sketched.

\section{Defining DfHF}

DfHF aims to build on Dilani’s (2005) efforts to interpret Salutogenesis as the starting point for theoretical approaches for design, by focussing on the question of what can help to flourish. Thus, DfHF, is also characterized by a fully positive starting point, and a design focus on augmenting the positive, as visualized by the slider pointing at 'stimulating positive' in Figure 1.

An environment designed via DfHF should offer people chances that help users to exploit talents and skills, but also challenge them to alter goals and further develop

\footnotetext{
${ }^{4}$ Note that no numbers or scales are used in this Figure, since this is purposed to give a visual impression of the range of the attributes per paradigm.
} 
talents, and fulfil certain psychological needs (see Author, 2018). This implies, that designers will need to invest time in getting to know the psychological needs of the user(s), and interpreting and rewriting this knowledge into action possibilities or programmatic features. Design efforts will then be directed at creating spaces that incite, stimulate and challenge people to apply their talents and empower themselves through these offered activities. Thus, by asking oneself what a space must allow one to experience, what it spurs one to do and how all of that incites one to become the best possible person one can be, the design outcome of DfHF will concern an indirect influence of space. This means that an effect is generated that takes place after an intensive contact with the environment through participating in its -intangibleactivities, and not primarily by a direct sensorial interpretation of the spatial reality. Therefore, in Figure 1, the slider is positioned almost completely towards 'intangible outcome - indirect influence of space', since the outcome -the action possibilities- is essentially of an intangible nature.

The effect aimed for by DfHF is flourishing, which is a psychological process, rather than a physical one (see Figure 1). Although DfHF does not aim to directly affect people's physical, medical health, it needs to be acknowledged that there can be a resulting effect on physical or medical well-being, because research has shown that ‘happy’ people can be more healthy people (see Lyubomirsky, 2005a,b, 2007; Veenhoven, 2008).

Regarding the durability of the designed effect, DfHF aims to design activities that assist people in training and developing skills and talents, which is a long-lasting effect (see Figure 1), which still provides benefits after they have left the environment. The emphasis is placed on empowering oneself, which is a prolonging process of positive internal change. Inherently, HF-architecture is designed on the assumption that 
a person can and will change, build skills, discover new skills, and consequently alter his/her goals and develop new needs. Of course, a HF-environment can also provide the temporary experience of hedonic pleasure, but the main goal is a durable effect, which outlives a presence in the designed environment, therefore, the respective slider in Figure 1 is positioned mainly towards 'long-lasting effect - internal change’.

Concerning the scope, DfHF is user-dependent, as the design sprouts out of the psychological characteristics of the user. DfHF handles a demarcated group with a binding component that often corresponds with the main program of a building, for instance 'older persons' in residential care. The target group can vary between broad or narrow. However, the designer should approach this group in a broad sense, since a profound study of the needs and talents of this target group incorporates anticipating on their changing needs and developed talents, to help them flourish. Thus, in the design process, the heterogeneity found within target groups will be most important. As visualized in Figure 1, the slider slightly tilts towards heterogeneity.

\section{[Figure 1 near here]}

Figure 1: Interpretation of DfHF in the light of five attributes

\section{A DfHF design example}

A DfHF example was found in the "outdoor promenade" of the Astor project ${ }^{5}$ Haacht, Belgium. Described architecturally, it is an outdoor passageway that enfolds each building layer, and is the way to access the residents' private living quarters situated on

\footnotetext{
${ }^{5}$ Astor projects are care residences developed from a specific demand-driven care concept (see
} OSAR, 2017). 
the upper levels above ground floor. One can say that it is designed to provide access, however design effort regarding empowering experiences for older persons gave rise to this physical realization. To illustrate what DfHF can mean, this example will be discussed based on coded data from an in-depth interview held with the main architect (M. $)^{\mathrm{i}}$, in which the design process of the Astor residence was discussed through a wellbeing lens.

\section{[Figure 2 near here]}

Figure 2: Sketch of the outdoor promenade, visualized from the inner square

Tapping from his own images of residential care, architect (M.) felt that a more empowering and positively appraised situation could be realized within the aspect of (vertical) circulation, since often, this happens via an indoor elevator leaving no reason to go outside in the fall and winter seasons. The designer recognized the opportunity to incorporate another more creative interpretation of aspects of physical training offered in traditional residential care centres to the concept of circulation. Also, he saw opportunities to help residents stay in touch with the village or city life even during fall and winter seasons, and at least feel the societal ambiance of Haacht. As evidenced, three important psychological needs of older persons were surfaced here by the architect: (1) stay active, (2) fight loneliness and (3) remain part of society.

To address these, (M.) firstly foresaw a situation in which people that are doing groceries or simply walk around in the city centre are brought in 'contact' with residents, in different intensities. Concretely, a situation was created in which passersby can take a pedestrian shortcut on their own route through town that passes through 
the Astor residence. On a planning level, a building block was designed that is cut by an inner square, conceived as a public passageway. The designer imagined different intensities to perpetuate possible social contact between residents in their private space and the passers-by in the square, facilitated by an 'outdoor promenade' that circles the building block. That way, a semi-public transitional space is realized attached to the apartments from where to overview, call out and go to people in the square. Moreover, on the level of the building itself, the private apartments are designed in a way that the front doors all face towards the inner square, where the outdoor promenade is situated, making that the only circulation route for residents to travel from their apartment to the communal spaces on the ground floor or the inner square. This way, residents are nudged to walk the walk towards the outdoor elevator and feel the outside world.

Thus, the design interventions that led to the physical outdoor promenade serve at least three intangible outcomes that fulfil the surfaced psychological needs, namely (1) nudging people to stay physically active in a natural way without the stigma of 'having to go to physical therapy', (2) offering people a way to experience different intensities of social contact and involvement: from observing by using the promenade as a private terrace space, to seeking contact with neighbours by viewing it as a meeting place, to seeking contact while being physically in different zones by calling out to people, or even joining in public life at the inner square, and (3) staying in touch with real life by means of experiencing the seasonal changes and the weather conditions, a crucial aspect of life.

\section{[Figure 3 near here]}

Figure 3: Visualisation of the passageway 
The physical design result might not seem innovative, however the way it arose and the intangible results, as in what it affords, are. Concretely, the design process is characterized by departing from a positive design approach, that generates psychological positive influences: challenging people to stay fit, keep them part of society, and in touch with 'real life' through feeling the seasonal changes, without losing oneself in negative aspects such as 'frail older persons should not be exposed to bad weather'. Thus having to walk outside in possibly bad weather -by some at first sight seen as a 'physical burden'- here instigates a long(er)-lasting effects that cause positive internal changes in the users, by allowing them to train their physical prowess in keeping 'fit', and their mental and social prowess by soaking in outside atmosphere and training their social skills in various ways.

While this is a novel approach, roots of this line of thinking can be traced back to Modernist thinking. The ideas to base oneself on specific needs of target groups can already be recognized in for instance some of the criteria of the checklist for masshousing in the 1960s developed by Team-X-architects Peter and Alison Smithson: e.g. 'Is there a place where a 3-5 year old can play?’ (Smithson \& Smithson, 1957/9). This list incorporated aspects of emotional and psychological well-being, hinting at the responsibility architects had according to them towards residents. More specifically in this example, the social atmosphere that is carefully designed, also echoes interventions in the 'grand ensembles' designs in which a social ambiance initially did not seem to come natural. As a reaction, designers understood the need to animate people: people should no longer be seen as passive users or beneficiaries, but as active constituents (Cupers, 2010). Here, in that light, but on a much smaller scale and from a more zoomed-in humane perspective, the inner square and its passers-by indeed succeed in 
giving life to the building, and creating a vital process in which residents can affirm themselves.

\section{Discussion and conclusion}

In this paper, the purpose was to propose a structured design approach -DfHF- to answer to the current momentum that steered architecture on a more 'humane' course. First, that momentum has been unravelled, and the concept of flourishing was pushed forward to build a design approach on. Then, DfHF has been defined in human-centred design via five attributes distilled from well-being literature and confronted with the design discipline of architecture. DfHF has thereby been given proper characteristics with regards to the (i) the designer's vision and focus (ii) the effect aimed for through architecture, (iii) and the actual design outcome’s nature. DfHF herein takes a specific combination of stands regarding the five attributes and thus takes up a unique place in human-centred architectural design. The combination of the architect's focus on 'stimulating the positive' in the design process, an aimed long-lasting effect on the users and the intangible character of the eventual architectural realizations cannot be found in other paradigms or design approaches.

Introducing DfHF contributes to the body of theory of both well-being research and design sciences. A number of advantages that provide important avenues for further research can be summed up:

Firstly, with this particular lens of five attributes, we aimed to offer an alternative and additional perspective to human-centred design. This approach complements the more methodological lens and exploration of the field by Sanders and Stappers (2008), who focus on the people who take the design initiative. In that respect, making an elaborate comparison between DfHF and paradigms and approaches that show close affinity with DfHF through their specific stands towards well-being, can 
help in further illuminating the human-centred architectural field in a different manner. Rendering a 'humane' identity card per paradigm -as is done for DfHF-, can even be hypothesized to also help designers to choose more suitable design approaches to tackle specific challenges that they are confronted with. The polyhedron visualizes the specific characteristics per paradigm, that might be matched with particularities deducted from a design brief, in order to find the best fit between the design challenge and a design approach.

Secondly, architects today often rely on their intuition while incorporating wellbeing related aspects into their design, or they practice this theme without being formally aware of it (as was the case with the 'outdoor promenade'). As such, the introduction of DfHF can be viewed as a step towards developing a systematic approach. Crucial in this respect is to enable architects to think and design in terms of positive challenges and opportunities that spaces have to offer to users. However, to integrate DfHF as a practical design approach, more research should be performed on how to blend theoretical knowledge concerning flourishing and practical designerly knowledge so that it can be efficiently integrated in architectural design processes. Additionally, to further concretize the DfHF-paradigm, specific HF-information for specified target groups needs to be developed through research, and made available to architects.

Thirdly, the current vagueness of architectural approaches regarding well-being issues complicates communicating relevant design features to stakeholders. When explicated further, DfHF can provide a vocabulary that stresses the value of well-being and flourishing in the built environment. 
Limitations of this study are firstly relating to the set-up of this study: the research is based on contemporary research results in the field of well-being and flourishing, however we foresee progressing insights to be developed due to the novelty of the research field. Secondly, as the first author has an architectural background, this study and interpretation of well-being theory (originating mainly in psychology), is rather specific and infused by a particular designerly viewpoint.

\section{References}

Author. 2018.

Antonovsky, Aaron. 1979. Health, Stress and coping: new perspectives on mental and physical well- being. San Francisco: Jossey-Bass.

Antonovsky, Aaron. 1996. "The salutogenetic model as a theory to guide health promotion.” Health promotion international 11 (1): 11-18.

Aravena, Alejandro. (2014). TED talk by Alejandro Aravena "My architectural philosophy? Bring the community into the process.”. Accessed 4 November 2017.

http://www.ted.com/talks/alejandro aravena my architectural philosophy bring the co mmunity into the process

Architects Sans Frontières Belgium. 2017. Website of organization “Architecten zonder Grenzen - Belgium”. Accessed 5 December 2017. http://www.asfint.org/asfmember/asf-belgium/

Attiwill, Suzy. 2013. “Urban. Interior. Craft. A World in Making.” Making Futures Journal 3: 374-387.

Bogers, Tetske, Juriaan van Meel, and Theo van der Voordt. 2008. “Architects about briefing” Facilities 26 (3/4): 109-116.

Brey, Philip. 2015. “Design for the Value of Human Well-Being”. In Handbook of Ethics, Values, and Technological Design. Sources, Theory, Values and Application Domains, edited by Jeroen van den Hoven, Pieter Vermaas \& Ibo van de Poel, 365-382. Springer.

Brolin, Brent. 1976. The Failure of Modern Architecture. London: Vista.

Cupers, Kenny. 2010. “Designing Social Life: The Urbanism of the Grand ensembles”, Positions, 1: 95-121. 
De Ridder, Roel. 2016. “De Waarde van het Hasseltse Begijnhof”. Accessed 5 December 2017. http://architectuurwijzer.be/de-waarde-van-het-hasseltsebegijnhof/

Desmet, Pieter, and Anna Pohlmeyer. 2013. "Positive design: An introduction to design for subjective well-being.” International Journal of Design, 7(3): 5-19.

Diener, Ed, Jeffrey Sapyta and Eunkook Suh. 1998. "Subjective well-being is essential to well-being.” Psychol. Inq. 9: 33-37.

Diener, Ed, Eunkook Suh, Richard Lucas, and Heidi Smith. 1999. "Subjective wellbeing: three decades of progress.” Psychological Bulletin 125 (2): 276-302.

Dilani, Alan. 2005. “A new paradigm of design and health in hospital planning.” World Hospitals and Health Services, International Hospital Federation 41 (4): 17-21.

Elemental. 2017. Website of the “Do Tank Elemental”, by Pritzker Price 2016 winner Alejandro Aravena. Accessed 5 October 2017. http://www.elementalchile.cl/en/.

Eriksson, Monica, and Bengt Lindström. 2012. "Salutogenesis and Resilience - two sides of the same coin?” Psychology and Health. 27.

Hadelich, Valentin. 2012. “Quality by design: The Venustas of urban squares. Objectifying cause and effect in the design and succes of urban squares”, in Proceedings of the Congress for New Urbanism 20, Florida, USA.

Headey, Bruce, Elsie Holmstrom, and Alexander Wearing. 1985. "Models of well-being and ill-being.” Social Indicators Research, 17, 211-234.

Holl, Steven, Juhani Pallasmaa and Alberto Pérez-Gómez. 2007. Questions of Perception: Phenomenology of Architecture. San Francisco: William Stout Publishers.

Huppert, Felicia, and Timothy So. 2013. "Flourishing Across Europe: Application of a New Conceptual Framework for Defining Well-Being.” Social Indicator Research 110: 837-861.

Kahneman, Daniel. 1999. “Objective happiness.” In Well-being: The foundations of hedonic psychology, edited by Daniel Kahneman, Ed Diener \& Norbert Schwarz, 3-25. New York: Russell Sage.

Keyes, Corey. 2002. "The mental health continuum: From languishing to flourishing in life.” Journal of Health and Behavior Research, 43: 207-222.

Keyes, Corey. 2007. "Promoting and protecting mental health as flourishing: a complementary strategy for improving national mental health.” Am Psychol, 62 (2): 95-108. 
Koolhaas, Rem. 2016. “The future of the ways we live and work.” Accessed 8 June 2016. https://www.zeitgeistminds.com/talk/4926389362884608/rem-koolhaas-thefuture-of-the-way-we-live-love-and-work-rem-koolhaas

Lang, Jon. 1987. Creating architectural theory: The role of the behavioural sciences in environmental design. Van Nostrand Reinhold.

Lindström, Bengt, and Monica Eriksson. 2005. "Salutogenesis.” Journal of Epidemiol Community Health, 59 (6): 440-442.

Lindström, Bengt, and Monica Eriksson. 2008. "Salutogenesis - Health in the River of Life.” [In Swedish]. Suomen Lääkärilehti, 63 (6): 519a-519b.

Lindström, Bengt, Monica Eriksson and Folkhälsan, Research Centre Health Promotion Research \& International Promotion and Education Global Working Group on Salutogenesis. 2010. The Hitchhiker's Guide to Salutogenesis. Salutogenic pathways to health promotion. Helsinki: Folkhälsan.

Lyubomirsky, Sonja. 2007. The how of happiness: A new approach to getting the life you want. New York: Penguin Books.

Lyubomirsky, Sonja, Laura King, and Ed Diener. 2005a. "The benefits of frequent positive affect: does happiness lead to success?” Psychological Bulletin 131: 803-855.

Lyubomirsky, Sonja, Kennon Sheldon, and David Schkade. 2005b. "Pursuing happiness: the architecture of sustainable change.” Review of General Psychology 9 (2): 111-131.

Maggie’s Architectural Brief. 2011. Accessed 13 April 2015. http://www.maggiescentres.org/about/our publications.html

Maier, Jonathan, Georges Fadel, and Dina Battisto. 2009. “An affordance-based approach to architectural theory, design, and practice.” Design Studies 30 (4): 393-414.

Maslow, Abraham. 1954. Motivation and personality. New York, NY: Harper.

OMA. 2017. Website of the international architectural firm “Office for Metropolotan Architecture”. Accessed 5 October 2017. http://oma.eu/office.

Oppliger, Matthias. 2015. “Jan Gehl: 'Architects know very little about people’”. Tages Woche, March 18. Accessed 13 April 2015. http://www.tageswoche.ch/+fmm3q. OSAR. (2017). Website of the Belgian architectural firm OSAR. Accessible on http://www.osar.be/pages/blog.php. 
Pallasmaa, Juhani. 2005. The eyes of the skin, Architecture and the senses. West Sussex: Wiley.

Rosenman, Michael and John Gero. 1998. "Purpose and function in design: From the socio-cultural to the techno-physical.” Design Studies 19: 161-186.

Ryan, Richard, and Edward Deci. 2000. "Self-determination theory and the facilitation of intrinsic motivation, social development, and well-being.” American Psychologist 55 (1): 68-78.

Ryff, Carol. 1989. "Happiness is everything, or is it? Explorations on the meaning of psychological well- being.” Journal of Personality and Social Psychology 57: 1069-1081.

Ryff, Carol, and Burton Singer. 1998. “The contours of positive human health. Psychological inquiry.” 9 (1): 1-28. http://www.tandfonline.com/doi/abs/10.1207/s15327965pli0901_1

Ryff, Carol, and Corey Keyes. 1995. “The structure of psychological well-being revisited.” Journal of Personality and Social Psychology 69 (4): 719-727.

Saleebey, Dennis. 2006. Strengths perspective in social work practice. Boston, MA: Allyn \& Bacon/Longman.

Schotanus-Dijkstra, Marijke, Pieterse, M.E., Drossaerts, C.H.C., Westerhof, G.J., de Graaf, R., ten Have, M., Walburg, J.A., Bohlmeijer, E.T. 2016. "What factor are associated with flourishing? Results from a large representative national sample.” Journal of Happiness Studies 17: 1351

Seligman, Martin. 2011. Flourish: A Visionary New Understanding of Happiness and Well- being. New York: Free Press.

Silva, Kapila. 2011. "Mapping leaning in the city image: A case study of Kandy, Sri Lanka.” Journal of architectural and planning research 28 (3): 229-251.

Smithon, Peter, Smithson, Alison. 1957/9. Criteria for Mass Housing.

Stringer, P. 1980. "Models of man in Casterbridge and Milton Keynes.” In Architecture for people, edited by Byrion Mikellides, 176-186. New York: Holt, Rinehart and Winston.

Tétreault, Marie-Hélène, and Romedi Passini. (2003. “Architects' use of information in designing therapeutic environments.” Journal of Architectural and Planning Research 20: 48-56.

Tiberius, Valerie. 2006. "Well-being: Psychological research for philosophers.” Philosophy Compass 1: 493-505. 
Van der Linden, Valerie, Margot Annemans, and Ann Heylighen. 2016. “Architects’ approaches to healing environments in designing a Maggie’s Cancer Caring centre.” The Design Journal 3: 511-533.

Veenhoven, Ruud. 2008. "Healthy happiness: Effects of happiness on physical health and the consequences for preventive health care.” Journal of Happiness Studies, 9 (3): 449-464.

WHO. (2001). Fifty-fourth World Health Assembly. Geneva: World Health Organization. Accessed 8 April 2016.

http://www.who.int/schistosomiasis/resources/wha/en/

Table 1: List of comparing attributes and their continuum to profile human-centred design paradigms in architectural practice

\section{Attribute manifests itself in:}

Nature of the design process'

starting vision \& mindset

Nature of the design outcome

Nature of the generated effect

Generosity of the generated effect

Approach of user group in the design process
Comparing attributes and their continuum:

Compensating negative $\quad<->\quad$ Stimulating positive

Tangible outcome Direct influence of space

Physical effect

Fleeting effect

No internal chance

Narrow scope

rather homogeneous
<-> Psycho-emotional effect

<-> Long-lasting effect Internal change

<-> Broad scope

<-> Intangible outcome Indirect influence of space rather heterogeneous 


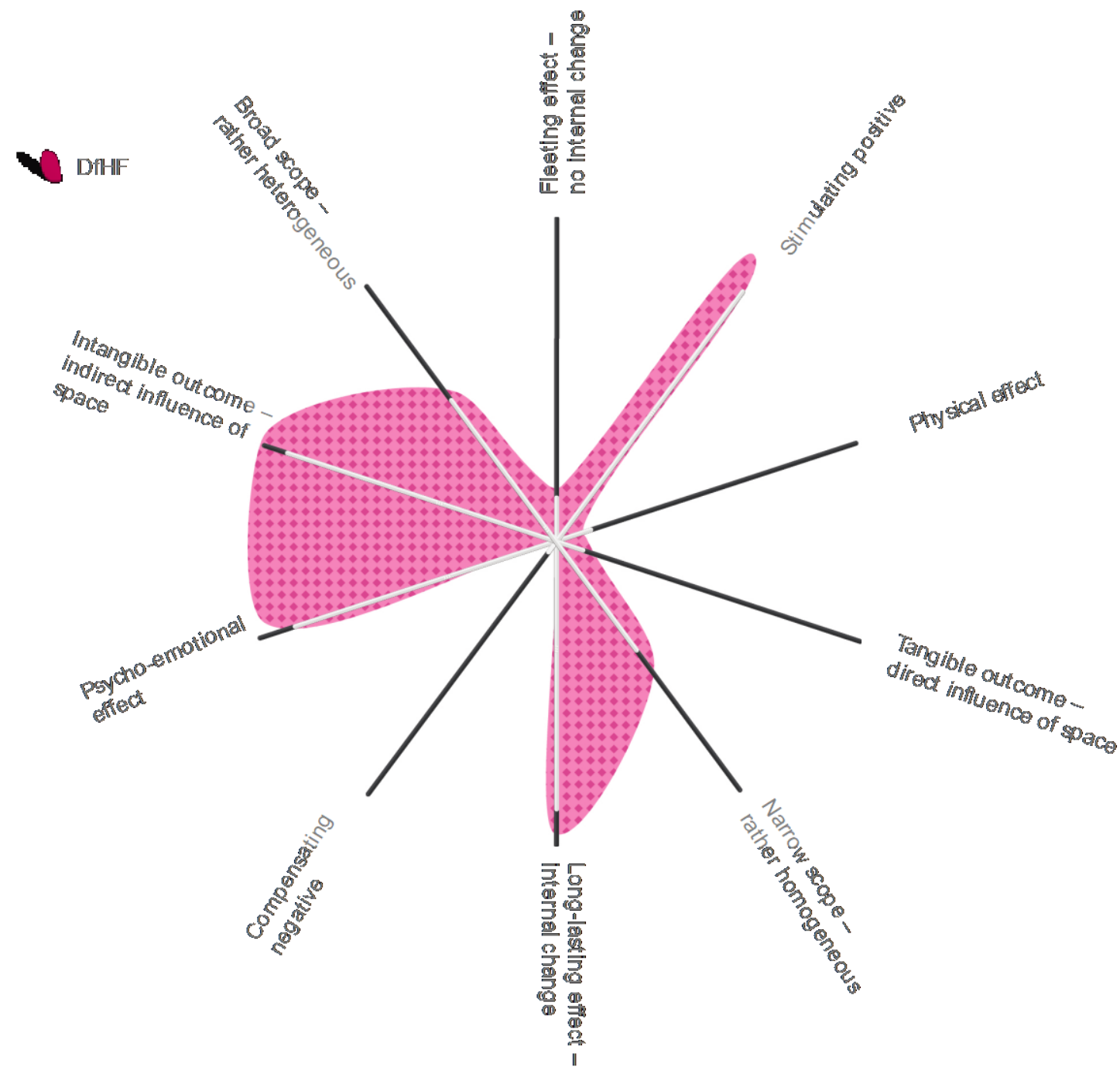

Figure 1: Interpretation of DfHF in the light of five attributes 


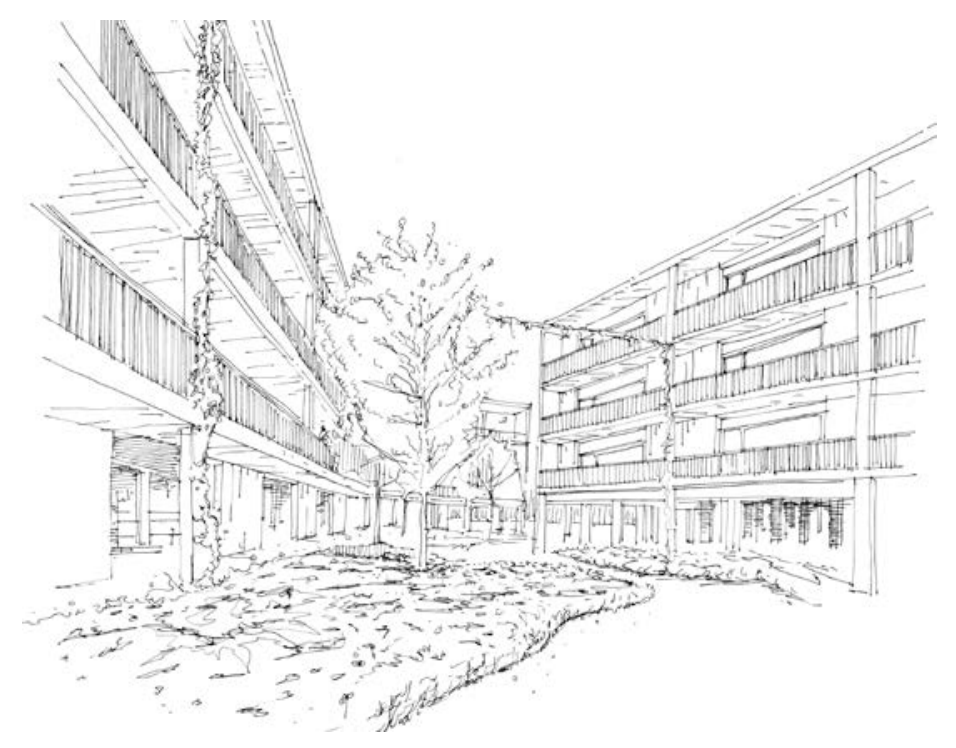

Figure 2: Sketch of the outdoor promenade, visualized from the inner square

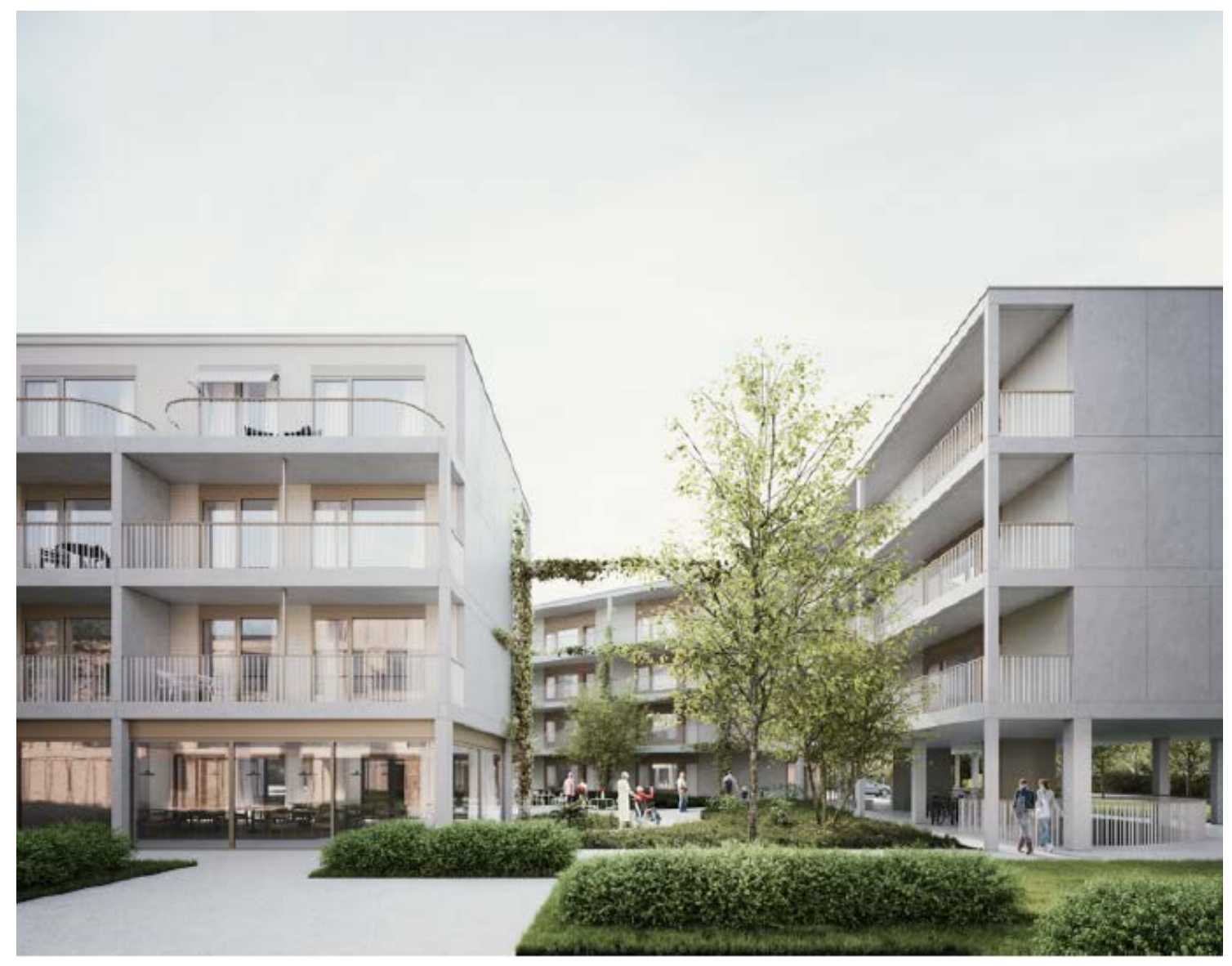

Figure 3: Visualisation of the passageway (copyright OSAR architects) 
${ }^{\text {i }}$ On the design, designer (M) said the following: Somebody in a classic RCC doesn't go outside all winter long, not even once, just not... To keep active by sitting in a circle and pitching small balls.... In Astor, you walk by foot towards the elevator (on the outdoor promenade) that takes you downstairs to the service centre. And in the evening, you go back. That is a way of physical training as well, but it is much more personal and different. Yes, I believe in the 'humane' qualitative approach.... Because, the flat that is located the furthest from the elevator, that might take half an hour if you want to do it by foot, but meanwhile, you look out onto the inner garden, that is important, you walk on the promenade and you see all those people. Or the other way around, in summer, or when it is good weather and not too chill, you can sit in front of your front door, on the promenade, and look at what happens at the inner square, without having to physically join in. 